\title{
RNA-binding proteins regulate aldosterone homeostasis in human steroidogenic cells
}

\author{
RUI FU, ${ }^{1,4}$ KIMBERLY WELLMAN, ${ }^{1,4}$ AMBER BALDWIN, ${ }^{1}$ JUILEE REGE, ${ }^{2}$ KATHRYN WALTERS, ${ }^{1}$ \\ ANTJE HIRSEKORN, ${ }^{3}$ KENT RIEMONDY, $^{1}$ WILLIAM E. RAINEY, ${ }^{2}$ and NEELANJAN MUKHERJEE ${ }^{1}$ \\ ${ }^{1}$ RNA Bioscience Initiative, University of Colorado School of Medicine, Aurora, Colorado 80045, USA \\ ${ }^{2}$ University of Michigan School of Medicine, Ann Arbor, Michigan 48109, USA \\ ${ }^{3}$ Max Delbrück Center for Molecular Medicine, 13092 Berlin, Germany
}

\begin{abstract}
Angiotensin II (Angll) stimulates adrenocortical cells to produce aldosterone, a master regulator of blood pressure. Despite extensive characterization of the transcriptional and enzymatic control of adrenocortical steroidogenesis, there are still major gaps in the precise regulation of Angll-induced gene expression kinetics. Specifically, we do not know the regulatory contribution of RNA-binding proteins (RBPs) and RNA decay, which can control the timing of stimulus-induced gene expression. To investigate this question, we performed a high-resolution RNA-seq time course of the Angll stimulation response and 4-thiouridine pulse labeling in a steroidogenic human cell line (H295R). We identified twelve temporally distinct gene expression responses that contained mRNA encoding proteins known to be important for various steps of aldosterone production, such as cAMP signaling components and steroidogenic enzymes. Angll response kinetics for many of these mRNAs revealed a coordinated increase in both synthesis and decay. These findings were validated in primary human adrenocortical cells stimulated ex vivo with Angll. Using a candidate screen, we identified a subset of RNAbinding protein and RNA decay factors that activate or repress Angll-stimulated aldosterone production. Among the repressors of aldosterone were BTG2, which promotes deadenylation and global RNA decay. BTG2 was induced in response to Angll stimulation and promoted the repression of $m$ RNAs encoding prosteroidogenic factors indicating the existence of an incoherent feedforward loop controlling aldosterone homeostasis. These data support a model in which coordinated increases in transcription and decay facilitate the major transcriptomic changes required to implement a prosteroidogenic expression program that actively resolves to prevent aldosterone overproduction.
\end{abstract}

Keywords: RNA decay; RNA-binding proteins; gene expression kinetics; transcriptomics; steroid hormone

\section{INTRODUCTION}

Angiotensin II (Angll) is a potent octapeptide hormone that binds to angiotensin II receptor type 1 (AGTR1) in adrenal zona glomerulosa cells to stimulate the production of the mineralocorticoid aldosterone from cholesterol. The primary function of aldosterone is to regulate blood pressure and volume through the control of renal salt excretion (Gross and Gysel 1954). Additional functions of aldosterone discovered more recently include directly mediating cardiac and vascular remodeling (Feldman 2014; Monticone et al. 2018). Aldosterone is a small, nonpolar, and hydrophobic steroid hormone that passes through the cell membrane upon production. Given the lack of intracellular aldosterone, it must be produced de novo in re-

${ }^{4}$ These authors contributed equally to this work.

Corresponding author: Neelanjan.Mukherjee@cuanschutz.edu

Article is online at http://www.rnajournal.org/cgi/doi/10.1261/rna. 078727.121. Freely available online through the RNA Open Access option. sponse to steroidogenic stimuli. Thus, it is critical to tightly control the timing and amount of de novo aldosterone production. Pathological aldosterone excess, such as in primary aldosteronism, leads to hypertension and increased cardiovascular risk in humans (Monticone et al. 2018; Nanba et al. 2019; Brown et al. 2020). Although the stimulatory effect of Angll upon aldosterone secretion has been extensively studied, the temporal regulation of the Angll response, which is critical for maintaining aldosterone homeostasis, remains poorly understood.

The temporal coordination of Angll-stimulated aldosterone biosynthesis is described in two stages: an "early regulatory step" (minutes) and a "late regulatory step" (hours) (Nogueira et al. 2009; Hattangady et al. 2012). The early regulatory step is characterized by rapid signaling pathways promoting cholesterol mobilization. A key part of

(C) $2021 \mathrm{Fu}$ et al. This article, published in RNA, is available under a Creative Commons License (Attribution 4.0 International), as described at http://creativecommons.org/licenses/by/4.0/. 
the early step is inducing the expression of Steroidogenic Acute Regulatory Protein (STAR) that transports cholesterol from the outer to inner mitochondrial membrane allowing for conversion by CYP11A1 into the pregnenolone, which is a precursor for the production of all steroid hormones including aldosterone. The late regulatory step is characterized by inducing the expression of steroid biosynthesis enzymes such as aldosterone synthase (CYP11B2). Although the temporal order of the Angll gene expression response underlies both regulatory steps, there has not been an examination of steroidogenic transcriptome dynamics with sufficient temporal resolution to systematically identify distinct response kinetics.

There are two prototypical examples of coordinated temporal expression responses that feature different regulatory strategies. One example utilizes a cascade of transcription factor activity to generate waves of temporal expression patterns. Transcriptional cascades have been observed in the yeast cell cycle and innate immune responses (Luscombe et al. 2004; Smale 2012). The other example relies on intrinsic differences in the stability between induced transcripts to generate sequential response patterns. Specifically, the time to peak response is inversely correlated with the stability of the transcript, and thus unstable RNAs will exhibit more rapid induction and return to baseline than stable RNAs (Palumbo et al. 2015). This post-transcriptionally regulated model of temporal coordination of response kinetics has been observed largely in immune and inflammation responses (Hao and Baltimore 2009; Elkon et al. 2010; Rabani et al. 2011). Interestingly, increasing the decay rate of transcriptionally induced RNAs results in a kinetic response with a quicker time to peak expression and return to baseline. This strategy of increasing synthesis and decay has been observed in the yeast oxidative stress response and immune activation of mouse dendritic cells (Shalem et al. 2008; Rabani et al. 2014). A lack of response resolution in both of those biological systems would lead to deleterious effects for the cell and organism, much like the uncontrolled resolution of aldosterone production.

RNA-binding proteins (RBPs) are a class of trans-acting regulatory factors that control all aspects of RNA metabolism (Gerstberger et al. 2014). Many RBPs have been shown to control the stability of mRNAs through interactions with cis-regulatory elements in the 3'-UTR of their target RNAs (Keene 2007). RBPs binding to AU-rich elements are one of the most well-characterized examples for the regulation of RNA stability and have been associated with controlling the temporal order and shape of immune response kinetics (Hao and Baltimore 2009; Elkon et al. 2010; Rabani et al. 2014). General regulators of RNA stability, such as factors that modify deadenylation, can also control the temporal response kinetics of induced RNAs and may do so in cardiac hypertrophy (Mauxion et al. 2008; Masumura et al. 2016; Stupfler et al. 2016). In spite of the importnace of RBPs in the regulation of decay, expression kinetics, and many other post-transcriptional processes, their role in Angll-mediated aldosterone production is poorly characterized.

To understand the molecular basis and role of RNA regulation on the kinetics of the Angll-aldosterone gene regulatory program, we measured transcriptome dynamics at high-resolution applying RNA-seq on a steroidogenic human cell line (H295R) stimulated with Angll. While transcriptional control was clearly prominent, RNA decay rates determined the time to maximal change in expression. Furthermore, we observed Angll-dependent increases in RNA decay for many transcriptionally induced RNAs, including those encoding key prosteroidogenic proteins. These findings were validated in primary human adrenocortical cells stimulated ex vivo. We identified RBPs and RNA decay factors that either activate or repress aldosterone production. Finally, we found that Angll-induced RNA decay factor BTG2 represses aldosterone production and promotes the clearance of steroidogenic RNAs. Together, these data support a model in which coordinated increases in transcription and RNA decay facilitates the major transcriptomic remodeling required to implement a prosteroidogenic gene expression program that is temporally restricted to prevent aldosterone overproduction.

\section{RESULTS}

\section{Identification of genes with temporally distinct Angll-response kinetics in H295R cells}

To delineate the temporal coordination of the Angll-induced gene expression response, we performed a highresolution (twelve time points in duplicate) Angll stimulation RNA-seq time course in H295R cells (Fig. 1A). Rather than poly(A)-enrichment, we performed rRNA depletion to enable measurement of both precursor and mature RNAs. The data were high quality as samples clustered first by replicates $(r \sim 0.99)$ and then time post-stimulation (Supplemental Fig. 1A,B). First, we focused on changes in mature RNA (sum of all mature transcripts per gene, Supplemental Table 1). PCA analysis clearly indicated differences in gene expression as early as $15 \mathrm{~min}$ with the largest remodeling of the transcriptome occurring $\sim 6-8 \mathrm{~h}$ poststimulation (Fig. 1B). Furthermore, the return toward the unstimulated state by $24 \mathrm{~h}$ suggests that this time course captures most of the Angll-induced changes in RNA levels in this system. Next, we determined the genes exhibiting statistically significant changes (FDR $\leq 0.001$ and greater than twofold change) in mature RNA expression at any time point of Angll treatment versus unstimulated ( $n=$ 2417). The changes in expression measured by RNA-seq were recapitulated $(R>0.95)$ by qRT-PCR for a subset of differentially expressed genes (Supplemental Fig. 1C). Differentially expressed coding and long-noncoding 
A
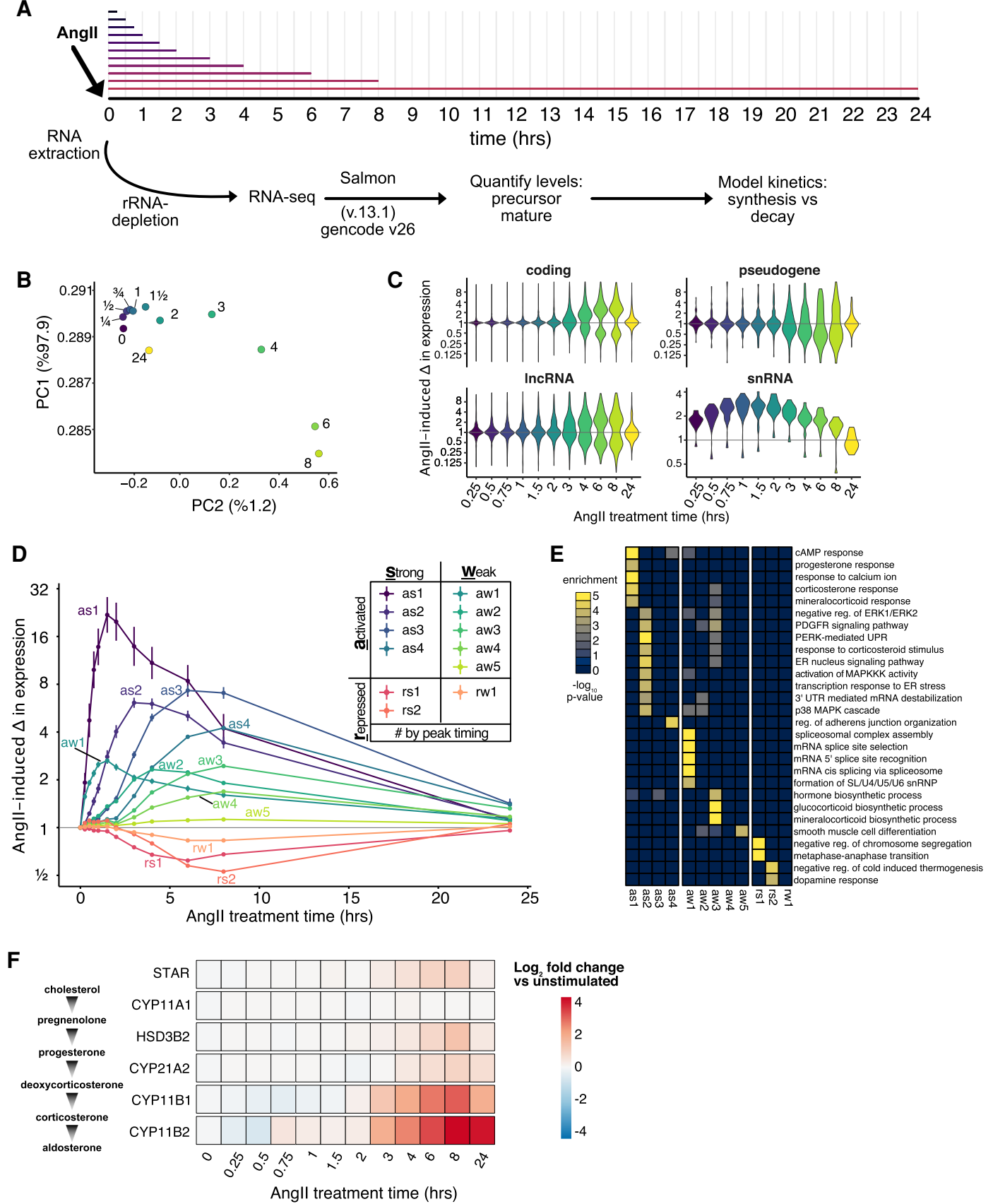

FIGURE 1. High-resolution Angll-response kinetics in H295R cells. (A) Cartoon of Angll treatment time course RNA-sequencing experiment. Total RNA is depleted for rRNA and precursor and mature RNA expression levels are calculated allowing modeling of synthesis and decay. (B) Scatter plot of the first two principal components calculated on a matrix of the mean expression level for each expressed gene at each time point (colors) after Angll stimulation. (C) Violin plot of the distribution of genes exhibiting statistically significant Angll-induced changes in expression per timepoint and category. (D) Line plot depicting the average change in expression (error bar represents standard error) relative to unstimulated cells for each group of genes with similar response kinetics determined by $k$-means clustering. Each color represents a specific group of genes with the name defined by the direction, shape, and timing of the Angll-induced response. (E) Heatmap of selected gene sets (Molecular Function ontology) that are significantly enriched in the Angll response groups. (F) Heatmap of log $_{2}$-based fold changes in pre-mRNA and mature mRNA levels upon Angll stimulation compared to unstimulated cells for mRNAs encoding key steroidogenic enzymes.

RNAs both exhibited the largest change in expression between 3 and $8 \mathrm{~h}$ (Fig. 1C). Intriguingly, snRNAs appeared to be up-regulated rapidly, peaking around $2 \mathrm{~h}$ before returning to baseline.
To identify genes with similar temporal changes in expression, we performed $K$-means clustering on the mature expression level changes for the differentially expressed genes. This revealed 12 groups of genes with temporally 
distinct Angll-response kinetics (Fig. 1D; Supplemental Fig. 1D; Supplemental Table 2). The groups were labeled based on the direction (activated/repressed), magnitude (strong/ weak), and timing of expression changes. For example, RNAs belonging to as1 (activated strong 1), exhibited an average maximal activation of $\sim 20$-fold peaking around 1 to $2 \mathrm{~h}$, while RNAs in as4 (activated strong 4) exhibited an average maximal activation of approximately fourfold peaking around $7 \mathrm{~h}$. The as1 RNAs encoded proteins involved in the calcium and cyclic AMP signaling pathway that are activated during steroidogenesis (Fig. 1E; Supplemental Fig. 1E), including NR4A1 and NR4A2, which are known transcriptional regulators of enzymes controlling aldosterone production (Bassett et al. 2004; Romero et al. 2004). Unexpectedly, we found a very strong enrichment for snRNAs, and particularly U1 snRNA, in aw1 (Supplemental Fig. 1F). We observed a strong enrichment in as2 for mRNAs encoding proteins regulating the unfolded protein response. RNA-binding proteins that control transcript-specific

RNA decay were enriched in as2 and aw2. The aw3 and as3 groups were enriched for mRNAs encoding steroid biosynthesis proteins. The induction of mRNAs encoding steroidogenic enzymes required for the conversion of cholesterol to aldosterone was consistent with previous studies validating the quality of the data (Fig. 1F; Romero et al. 2007; Wang et al. 2012). Altogether, our analysis demonstrated that Angll response kinetics exhibited temporal coordination of functionally related genes.

\section{RNA decay controls Angll response kinetics}

Simulations and previous studies in other stimulation-response paradigms have shown that the initial RNA decay rates in the unstimulated cells govern the time to peak expression response and thus the shape of the expression response (Rabani et al. 2011; Palumbo et al. 2015). Importantly, this phenomenon assumes constant decay rates throughout the response. As a starting point, we quantified the time to maximal expression change for each gene (see Materials and Methods), which increased concordantly with peak time assigned to each group (Fig. 2A, left). For example, genes in as1 (median $1.8 \mathrm{~h}$ ) reached their peak expression $5.7 \times$ faster than those in as4 (median 10.9 h). Next to test if RNA decay rates gov- erned maximal response kinetics in our system, we measured decay rates in unstimulated H295R cells using RNA metabolic labeling as we and others have done previously (Milek et al. 2017; Mukherjee et al. 2017). Cells were pulsed with 4-thiouridine (4sU) for $20 \mathrm{~min}$ and both total RNA and 4sU-labeled RNA were subject to rRNA depletion and RNA-sequencing, and synthesis, processing, and decay rates were calculated using INSPEcT for 11,668 genes in unstimulated H295R cells (Supplemental Fig. 2A-C; Supplemental Table 3; de Pretis et al. 2015). Our decay rates were consistent with established expectations for stable and unstable mRNAs confirming the validity of our measurements. As expected, transcripts encoding ribosomal proteins had low decay rates, while transcripts encoding immediate early genes had high decay rates (Supplemental Fig. 2D). We found higher decay rates for RNAs in clusters that peaked earlier post Angll stimulation (Fig. 2B, right). For example, RNAs in as1 had a $\sim 4.5 \times$ higher decay rate than RNAs in as4. Indeed, we observed an inverse relationship between the median decay rate and the median time to maximal induction for both strongly and weakly activated genes (Fig. 2B). These results demonstrated that initial RNA decay rates in unstimulated cells play an important role in shaping Angllresponse kinetics. 
Next, we ascertained putative regulatory mechanisms controlling RNA decay rates in steroidogenic cells. To identify possible RBPs or miRNAs regulating stability, we ranked $m R N A$ s by decay rates and used $c$ Words to identify 7-mers overrepresented in the 3'-UTR sequence of unstable and stable RNAs (Rasmussen et al. 2013). Most of the significantly enriched motifs were associated with unstable RNAs versus stable RNAs. Therefore, we scored the top 5007 mers associated with instability for matches to RBP recognition motifs from external databases. These analyses revealed a striking enrichment for RBPs binding AUrich elements (AREs), which are key determinants of RNA stability (Fig. 2C). We also observed enrichment for RBPs regulating splicing and export, such as U2AF2 and RALY. These data identify putative RBPs and RNA regulatory elements that regulate RNA stability in unstimulated H295R cells. Assuming constant RNA decay rates throughout the Angll-response, higher decay rates in the unstimulated cells inversely correlate with time to peak expression in response to Angll stimulation (Fig. 2B). Therefore, RBPs that control the RNA decay rates in unstimulated cells are important regulatory factors controlling Angll response kinetics and ultimately steroidogenesis.

\section{Increased RNA decay during steroidogenesis}

Having established the importance of initial RNA decay rates on Angll response kinetics, we next asked if there was evidence for changes in decay rate during the steroidogenic response. We compared changes in pre-mRNA versus mRNA levels to determine whether gene expression changes were better explained by transcriptional or posttranscriptional regulation. Specifically, we utilized reads aligning to introns versus exons to determine Angll-induced changes in levels of pre-mRNA and mRNA, respectively (Gaidatzis et al. 2015; Alkallas et al. 2017; Mukherjee et al. 2017, 2019). We added the entire precursor RNA sequence and treated it as an additional transcript isoform to specifically quantify precursor (Supplemental Table 4) and mature transcript levels using Salmon (Patro et al. 2017). As a first pass, we calculated the correlation between the changes in pre-mRNA and mRNA levels of genes encoding steroidogenic enzymes required for the conversion of cholesterol to aldosterone and found examples that are largely explained by changes in transcriptional regulation (high correlation), as well as examples indicative of changes in post-transcriptional regulation (low correlation) (Fig. 3A). The same analysis was performed on all 1500 differentially expressed genes with introns and sufficient intronic read support and revealed a broad distribution of correlation coefficients (Fig. 3B). Each temporal group had many genes with low or negative correlation, indicating that changes in transcriptional regulation alone cannot explain the mature RNA changes. We also performed cross-correlation to account for processing delays and observed simi- lar results (Supplemental Fig. 3A). These results suggested that many genes were experiencing stabilization or destabilization in response to Angll stimulation.

To test the extent and direction of changes in posttranscriptional regulation, we performed exon-intron-split analysis (EISA) using precursor and mature RNA estimates comparing all Angll-stimulated samples to the unstimulated baseline (see Materials and Methods; Supplemental Table 5; Gaidatzis et al. 2015). Filtering of the initial 2417 differentially expressed genes for the presence of introns and sufficient intronic read coverage resulted in 1194 genes that were analyzed. Among these genes a large majority $(84 \% n=223)$ showed evidence of mRNA destabilization. Destabilized transcripts were significantly overrepresented in activated genes that had peak expression between 4-8 h post Angll stimulation (as3, as4, aw2, aw3) (Fig. 3C). Next, we examined Angll-induced genes with evidence for destabilization focusing on as 4 and aw3, which contained many steroidogenic genes (Fig. 1E). The amplitude of Angll-induced changes in precursor RNA were similar between genes with (blue lines) and without evidence for destabilization (black lines), albeit the precursor RNAs for destabilized genes tend to peak earlier (Fig. 3D, left). However, the changes in the mature RNA of destabilized genes (blue lines) were clearly suppressed relative to genes without evidence for post-transcriptional regulation (black lines) (Fig. 3D, right). Included among the destabilized mRNAs were proteins encoding STAR, which is required for the proper and timely enzymatic conversion of cholesterol to steroid hormones, and MC2R (Lin et al. 1995), which is the ACTH receptor known to be induced by Angll stimulation (Fig. 3E; Lebrethon et al. 1994; Parmar et al. 2008). We identified potential RBPs responsible for the increased decay by searching for RBP binding motifs overrepresented in the $3^{\prime}$-UTR of destabilized mRNAs belonging to aw3 and other clusters (Fig. 3F; Supplemental Fig. 3B) enriched for destabilized mRNAs. Among these RBPs are known regulators of RNA decay ILF2, HNRNPL, CNOT4 of the CCR4-NOT deadenylation complex (Albert et al. 2000; Shim et al. 2002; Hui et al. 2003). None of the candidates exhibited differential expression in response to Angll, nevertheless their activity or protein levels could change in the absence of changes in mRNA levels. Altogether, we have identified hundreds of genes $(n=223)$ exhibiting coordinate increases in both transcription and RNA decay, including key steroidogenic genes, and putative RBPs regulating Angll-induced post-transcriptional regulatory dynamics.

\section{Ex vivo steroidogenic response in primary human adrenocortical cells}

Although the expression dynamics in H295R cells stimulated with Angll suggested a key role for RBP-mediated RNA decay, the extent to whether these expression changes 

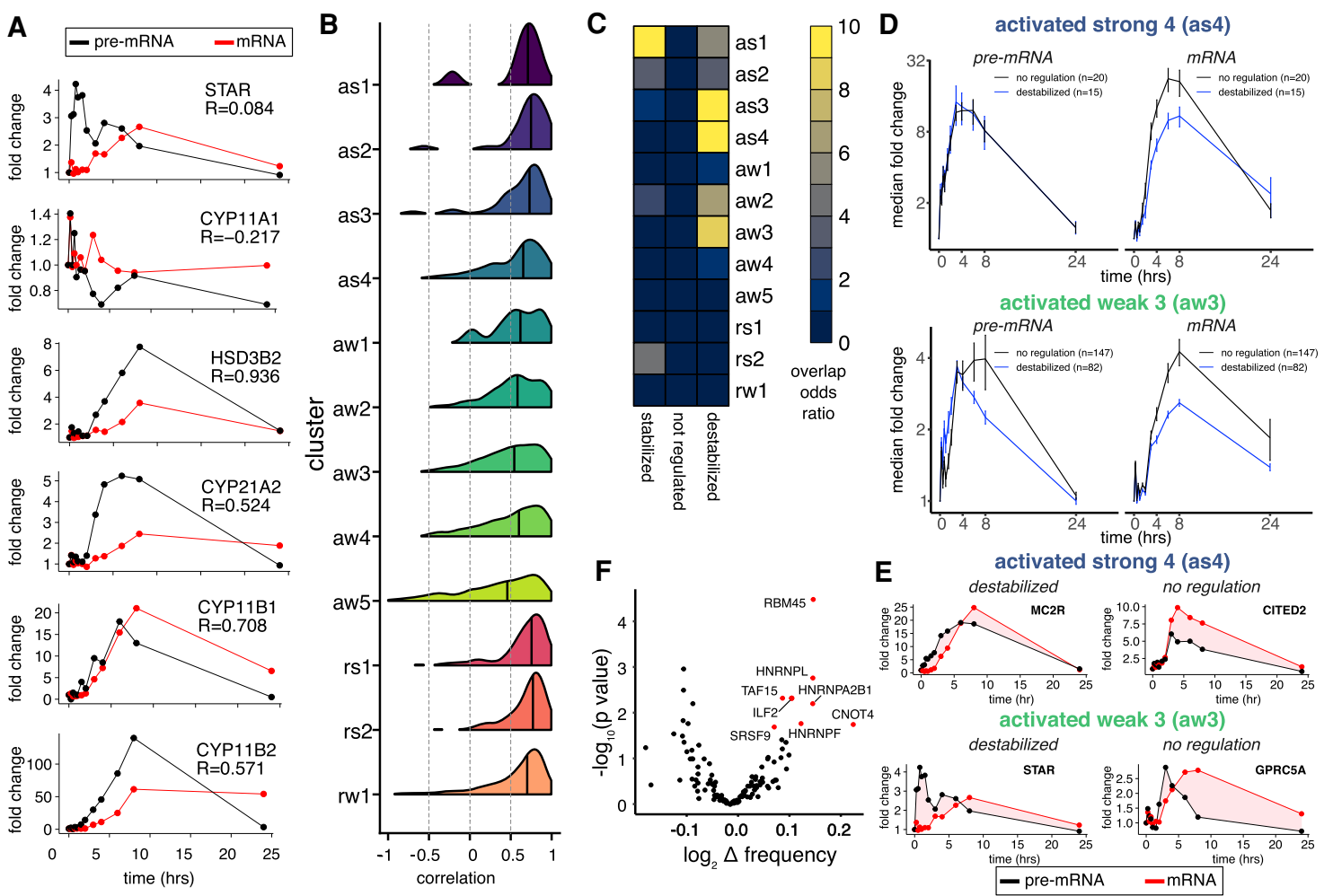

FIGURE 3. Dynamic changes in RNA decay during steroidogenesis. (A) Line plot of fold change in pre-mRNA (black) and mRNA (red) expression for mRNAs encoding enzymes responsible for conversion of cholesterol to aldosterone (top-to-bottom). Pearson correlation coefficient between changes pre-mRNA and mRNA for each gene (top right). (B) Distribution of Pearson correlation coefficient between pre-mRNA and mRNA changes for each gene across all time points for each response cluster. (C) Heatmap of the odds ratio for the overlap between response cluster membership and RNAs exhibiting evidence for stabilization, destabilization, or neither as determined by EISA (yellow indicates more overlap). (D) Line plot of median fold change in pre-mRNA (left) and mRNA (right) expression for genes in as4 (top) or aw3 (below) with either evidence for destabilization (blue) or no change in posttranscriptional regulation (black). Error bar represents standard error. (E) Line plot of mean fold change in premRNA (black) and mRNA (red) expression for example genes from as3 (top) or aw3 (below) and evidence for destabilization (left) or no difference in decay rates (right). (F) Scatter plot of the P-value and enrichment of RBP motifs in 5mers within the 3'-UTR of destabilized mRNAs in aw3 versus 3'UTRs of nondifferentially expressed mRNAs.

occur in normal human adrenocortical steroidogenesis is unclear. Therefore, we performed RNA-seq in adrenocortical cells isolated from the adrenal gland of a tissue donor and treated ex vivo with either Angll or ACTH or basal media for 3 or $24 \mathrm{~h}$ in triplicate (Fig. 4A; Supplemental Tables 6, 7; Xing et al. 2010, 2011). We included ACTH, which stimulates the production of cortisol by the zona fasciculata, because H295R cells do not correspond to a specific adrenocortical zone but produce cortisol and androgens in addition to aldosterone when stimulated with Angll (Parmar et al. 2008). Replicates were highly correlated and clustered by treatment condition and time (Supplemental Fig. 4A). PCA analysis revealed that compared to basal media cells treated with ACTH exhibited more differences than those treated with Angll (Fig. 4B). Across all conditions, we detected 3217 genes with significantly different expression levels (FDR <0.05). Consistently, we detected substantially more statistically significant expression changes induced by ACTH versus Angll at $3 \mathrm{~h}$ and 24 h (Supplemental Fig. 4B, left and right, respectively). How- ever, the expression changes for genes with significant differential expression upon either ACTH or Angll treatment $(n=3217)$ were strongly positively correlated. This indicated that the differences between ACTH and Angll were more quantitative (magnitude of the expression change) rather than qualitative (completely different genes changing) (Fig. 4C). Consistent with hormone production, both Angll and ACTH resulted in the induction of genes encoding key steroidogenic enzymes (Fig. 4D). Finally we tested if the Angll-induced changes were recapitulated in the ex vivo stimulation paradigm using gene set enrichment analysis (GSEA) (Tamayo et al. 2005). Indeed, as2 genes, which were robustly and rapidly induced by Angll in H295R cells, were significantly up-regulated after ex vivo treatment of primary adrenocortical cells with ACTH (Fig. 4E, top left) and Angll (Fig. 4E, bottom left) for $3 \mathrm{~h}$. Likewise, as 4 genes, which also exhibited a robust albeit delayed induction in response to Angll in H295R cells, were significantly up-regulated after ex vivo treatment of primary adrenocortical cells with ACTH (Fig. 4E, 

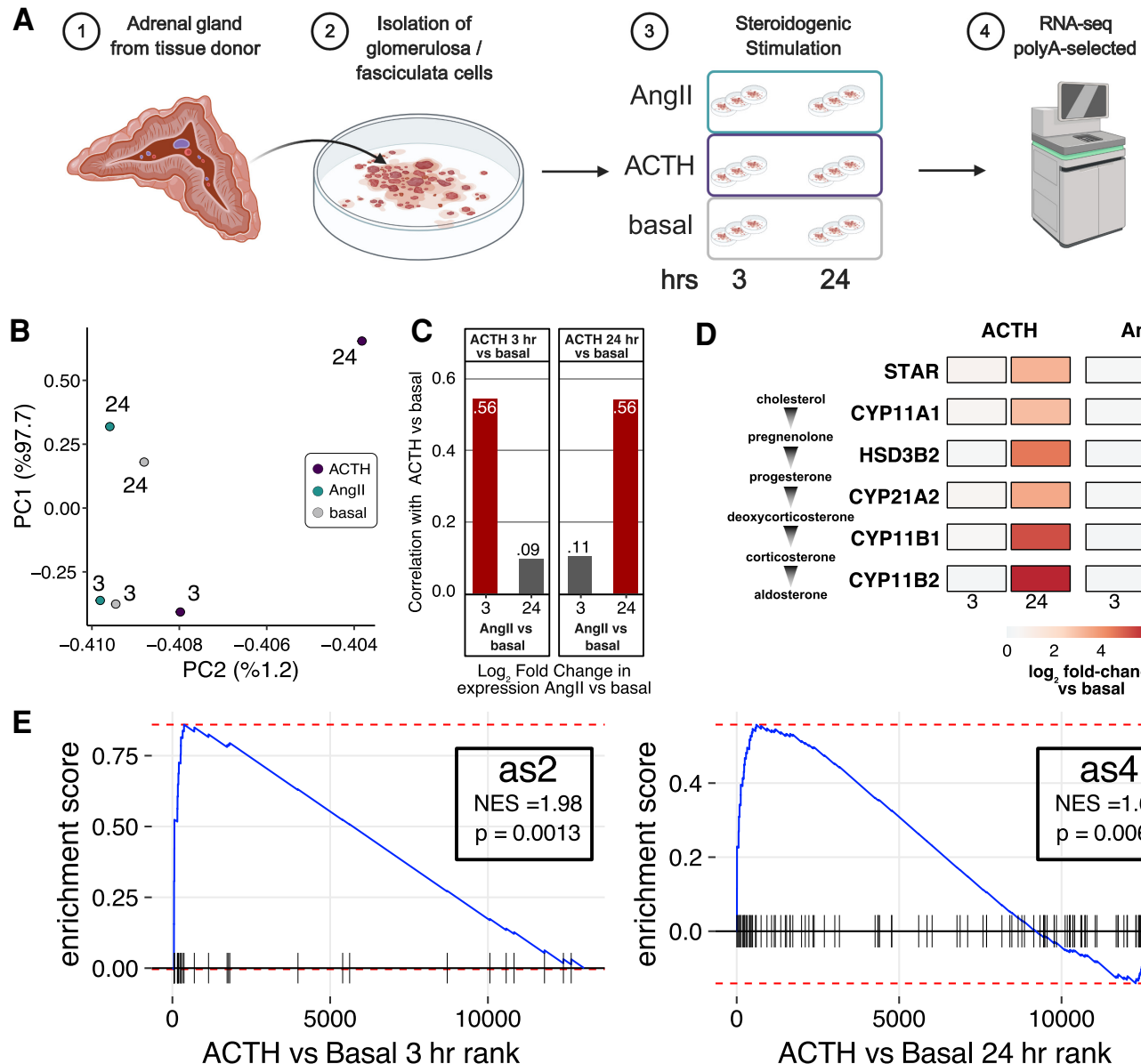

hrs $\quad 3 \quad 24$
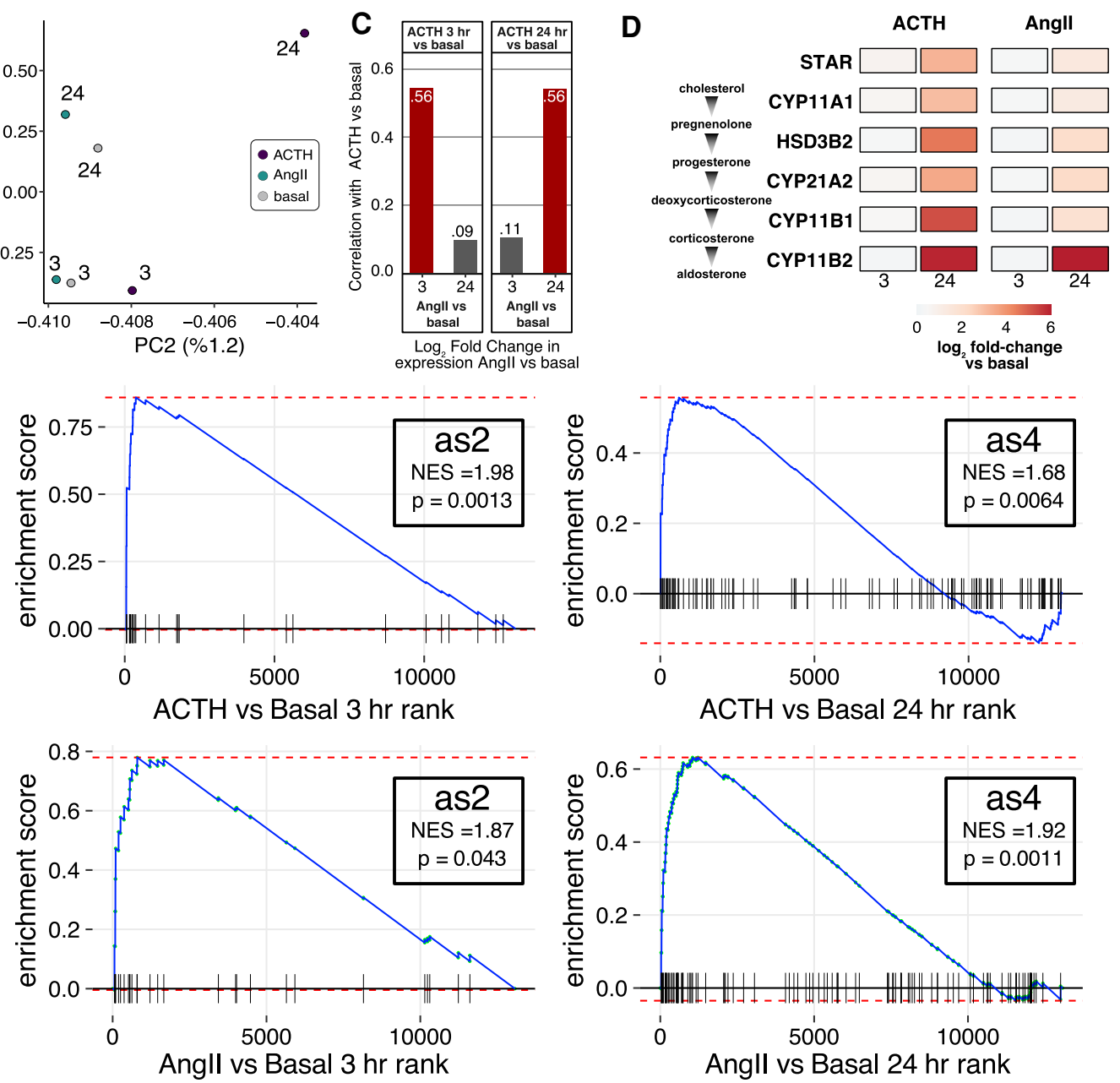

FIGURE 4. Gene expression dynamics of ex vivo stimulated primary human adrenocortical cells. (A) Ex vivo stimulation of cortical cells isolated from normal human adrenal glands treated with Angll, ACTH, or basal media for 3 or $24 \mathrm{~h}$. Strand-specific paired-end RNA-seq was performed in triplicate on polyadenylated RNA. (B) Scatter plot of the first two principal components calculated on a matrix of the mean expression level for each expressed gene at each time (label) and treatment (color). (C) Bar plot of the Pearson correlation coefficient between Angll-induced and ACTH-induced changes in gene expression versus basal cells for the union of genes exhibiting statistically significant changes in expression in

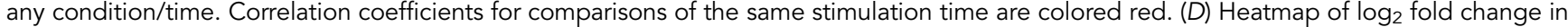
expression difference for stimulated (ACTH on left, Angll on right) versus basal for mRNAs encoding key steroidogenic enzymes. (E) GSEA running enrichment plots depicting the enrichment of as2 (left) and as4 (right) gene sets representing clusters of genes with similar Angll-induction kinetics in H295R cells (see Fig. 1D) in a list of genes ranked by the fold change upon ex vivo stimulation of primary human adrenocortical cells with $\mathrm{ACTH}$ (top) or Angll (basal) versus basal media.

top right) and Angll (Fig. 4E, bottom right) for $24 \mathrm{~h}$. We found 154 RBPs among the union of differential genes, including ones that were differentially expressed upon Angll treatment of H295R cells, such as CPEB4, MBNL1,
MBNL2, MSI2, PEG10, ZFP36, and ZFP36L2. Overall, we found strong concordance between the direction and timing of expression changes in H295R cells and primary cells (Supplemental Fig. 4C). 


\section{RNA-binding proteins regulate aldosterone levels}

Given the agreement in direction and timing of the steroidogenic gene expression response between H295R and primary human cells, we performed an siRNA screen to identify RBPs that regulate aldosterone levels in H295R cells. We selected 16 candidates from an annotated list of 1542 human RBPs (see Gerstberger et al. 2014) based on (i) differential expression upon Angll treatment in H295R cells; (ii) high expression in H295R cells; (iii) high and adrenal gland-specific RNA expression across normal human tissues; and (iv) RBP motifs enriched in the $3^{\prime}$-UTRs of unstable and destabilized mRNAs (Fig. 5A). Due to our inclusion criteria the candidate RBPs were not all known decay factors (e.g., TRUB1 or PELO). We used independent siRNAs for each candidate RBP and measured aldosterone levels in cell supernatants $24 \mathrm{~h}$ after treatment with either vehicle or Angll (see Materials and Methods for details). Aldosterone levels were normalized by cell viability and compared to a mock electroporation control for both unstimulated and stimulated cell supernatants (Supplemental Fig. 5A; Supplemental Table 8). As expected, the depletion of the key steroidogenic transcription factor SF-1 (NR5A1) resulted in loss of aldosterone. Five RBPs exhibited statistically significant increases in aldosterone levels by two independent siRNAs in Angll stimulated cell supernatants (Fig. 5B). Among these putative repressors of aldosterone were regulators of global RNA decay (BTG2), ARE-decay (ZFP36L1 and ZFP36L2), and a pseudouridine synthase (TRUB1). We identified three potential RBPs for which two independent siRNA knockdowns resulted in decreased aldosterone levels suggesting they promote aldosterone production (Fig. 5C). Specifically, these putative activators of aldosterone were a splicing factor (MBNL2), an RNA decay factor (CPEB4), and a signaling scaffold and RNA localization factor (AKAP1). For the seven other RBPs we either observed no change and/or conflicting results for the different siRNAs (HNRNPL, MBNL1, PEG10, PNRC2, ZFP36), or we only screened a single siRNA (MSI2 and PELO) (Fig. 5D). Knockdown of RBPs resulted in similar, but more subtle effects on aldosterone levels in unstimulated cells, which was to be expected given the minimal amounts of aldosterone produced in the absence of Angll (Supplemental Fig. 5BD). Interestingly we observed potential functional redundancy between the ZFP36 family members. Depletion ZFP36L2, which is the most abundant family member by mRNA expression, had the most consistent and potent increase in aldosterone levels (Supplemental Fig. 5E). These data revealed eight RBPs (10 including RBPs targeted by a single siRNA) that either activated or repressed aldosterone production. Seven of the ten RBPs were induced by Angll stimulation, which could indicate an increase in their respective post-transcriptional regulatory activity (Supplemental Fig. 5F).
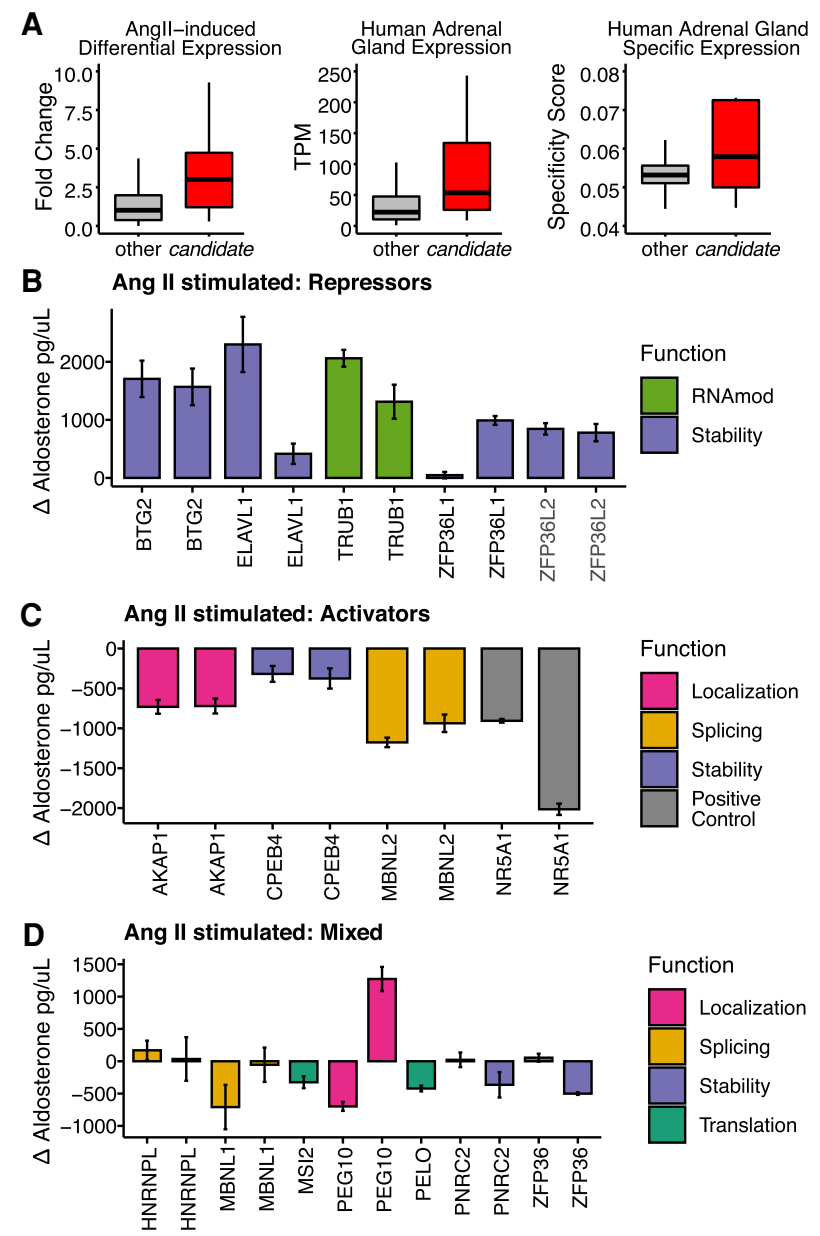

FIGURE 5. Regulation of aldosterone by RBPs in Angll stimulated cells. (A) Boxplots of all RBPs (gray) and candidate RBPs (red) for change in expression upon Angll stimulation (left), human adrenal tissue expression levels (center), and adrenal tissue specificity scores (right). Bar plot of the change in aldosterone concentrations for knockdowns resulting in $(B)$ increased aldosterone concentration, $(C)$ decreased aldosterone concentration, and (D) discordant or single siRNA results. Aldosterone levels were measured using ELISA from supernatants of H295R cells electroporated with siRNAs targeting candidate RBPs and stimulated with Angll for $24 \mathrm{~h}$. The $y$-axis represents the change in aldosterone concentration versus mock electroporation (see Materials and Methods). The error bars represent the standard error of at least six replicates. RBPs are color-coded by their known function.

\section{BTG2 temporally restricts Angll-induced activation kinetics}

We decided to investigate how BTG2 controls the Angll gene expression response. BTG2 promotes general RNA decay through deadenylation (Mauxion et al. 2008) and represses aldosterone production (Fig. 5B). Both BTG2 mRNA (Fig. 6A) and protein (Fig. 6B) were rapidly induced by Angll stimulation each peaking at $\sim 3 \mathrm{~h}$. Therefore, we hypothesize that BTG2 actively promotes the resolution of aldosterone production. We performed RNA-seq of siRNA knockdown of BTG2 in H295R cells 
A

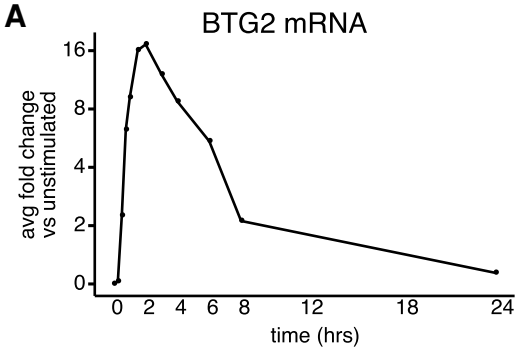

B

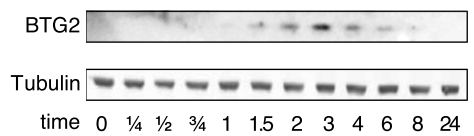

C

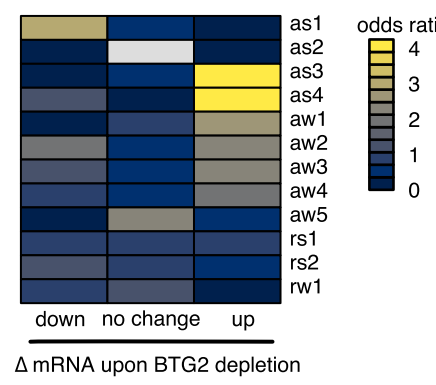

D
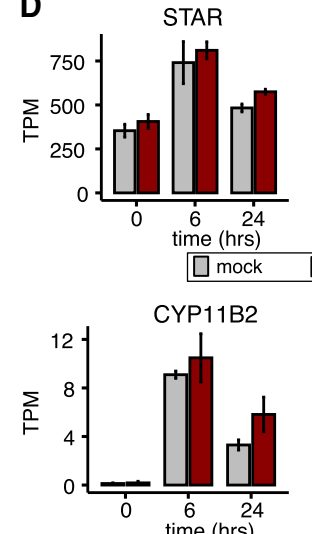

$E$
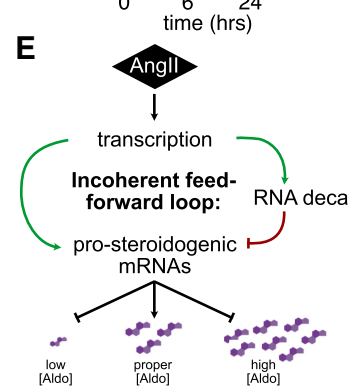
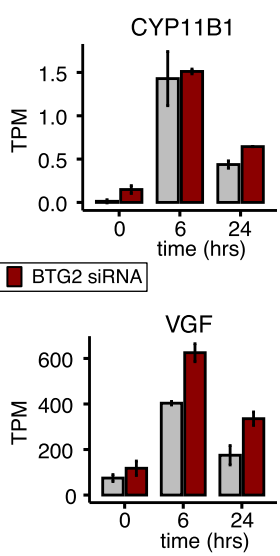

Incoherent feedforward loop:

- pulse-like response - faster response time - fold change detection - noise buffering

FIGURE 6. BTG2 constrains Angll RNA expression kinetics to prevent aldosterone overproduction. (A) Line plot of fold change in BTG2 mRNA levels in response to Angll. (B) Western blot of BTG2 and B-Tubulin protein levels in response to Angll. (C) Heatmap of the odds ratio for the overlap between response cluster membership and RNAs exhibiting down-regulation, no change, or up-regulation upon BTG2 siRNA depletion $24 \mathrm{~h}$ after Angll stimulation (yellow indicates more overlap). (D) Bar plot of expression levels of mRNAs encoding key Angll-induced steroidogenic proteins exhibiting statistically significant up-regulation $(P<0.05$, DESeq2) upon BTG2 siRNA depletion during Angll stimulation. Error bars represent standard deviation. (E) Model for incoherent feedforward loop using increases in transcription and RNA decay to coordinate Angll stimulation kinetics to ensure the appropriate production of aldosterone.

\section{DISCUSSION}

Despite our current understanding of adrenocortical steroidogenesis, the fundamental regulatory networks that govern aldosterone homeostasis remain unclear. Our data indicate that Angll stimulation increases both mRNA production and decay to rapidly implement and resolve a prosteroidogenic gene expression program. The Angll-induced expression dynamics in H295R cells are likely to be physiologically relevant since they were largely recapitulated in primary human adrenocortical cells stimulated with Angll and ACTH. This regulatory scheme enables the robust production of aldosterone while also preventing overproduction. The depletion of multiple factors promoting RNA decay, which themselves were up-regulated by Angll, resulted in an excess of aldosterone. The additional energy expenditure of increasing both transcription and decay may represent the cellular cost for the absence of a mechanism to store aldosterone within the cell and release it in response to stimulus. It will be interesting to determine if this coupling is disrupted by mutations driving primary aldosteronism. that were unstimulated or Angll-stimulated for $6 \mathrm{~h}$ and 24 $\mathrm{h}$ and performed RNA-seq in duplicate (Supplemental Table 9). As expected, BTG2 mRNA levels were lower across all time points in the BTG2 depletion compared to the mock depletion (Supplemental Fig. 6A). Next, we assessed the overlap between mRNAs up-regulated or down-regulated by BTG2 depletion with the Angll-response clusters. We found that mRNAs up-regulated upon BTG2 depletion were strongly enriched in the as3, as 4 classes and modestly enriched in aw1-aw4 classes (Fig. 6C). This is consistent with the propensity for these clusters to contain mRNAs exhibiting increases in RNA decay during steroidogenesis (Fig. 3C). Transcripts encoding critical prosteroidogenic factors and enzymes that were induced by Angll exhibited increased up-regulation in the BTG2 depleted cells (Fig. 6D), while unchanged mRNAs were not altered by BTG2 (Fig. 6D, right). Altogether, these data are consistent with a model in which BTG2 is induced by Angll to up-regulate the decay of mRNAs encoding prosteroidogenic factors to prevent overproduction of aldosterone.

\section{RNA decay temporally coordinates aldosterone production}

The stimulation response of adrenocortical cells to Angll resembles an impulse (or single pulse) pattern consistent with functional higher order temporal coordination. This system exhibits both regulatory modules (12 clusters in Fig. 1D), which consists of coexpressed genes with the same temporal pattern, which reflects a particular sequential order or cascade of gene or module expression (Yosef and Regev 2011). The mRNAs in the regulatory modules encoded functionally related proteins that play distinct roles at specific times during the Angll response. For example, expression levels of mRNAs encoding transcription factors and RBPs peaked within the first few hours, while those encoding steroidogenic enzymes peaked 6-8 $\mathrm{h}$ post stimulation. Indeed, the temporal coordination of expression of these distinct factors is consistent with previous characterization of early and late steps of steroidogenesis (Nogueira et al. 2009). Our data suggest that both transcriptional cascades and intrinsic differences in RNA decay 
rates determine the kinetics of the Angll gene expression response. Specifically, the decay rate of transcriptionally induced mRNAs is inversely proportional to the time to peak expression. Therefore, RNA decay is critical for temporally coordinating the response time of these regulatory modules and consequently aldosterone homeostasis. Our findings are similar to the observed role RNA decay in coordinating immune and inflammation responses (Hao and Baltimore 2009; Elkon et al. 2010; Rabani et al. 2011). The temporal coordination of these regulatory modules by post-transcriptional regulation may be examples of dynamic RNA regulons (Keene 2007). Interestingly, these observations occur in systems that require a robust, rapid, yet measured production of a physiologically potent molecule in either cytokines or steroid hormones.

\section{Coupling of transcription and decay dynamics controls aldosterone homeostasis}

Multiple lines of evidence indicate that one or more mixed incoherent feedforward loops (MIFFL) ensure the proper promotion and resolution of steroidogenesis (Fig. 6E). Specifically, Angll promotes the transcriptional up-regulation of both prosteroidogenic factors (STAR, CYP11B2) and RNA metabolism factors (BTG2, ZFP36L2) that negatively regulate the expression of prosteroidogenic factors. These Incoherent feedforward loops have largely been examined with respect to transcription factors and miRNAs and are a recurrent motif to enhance the robustness (Shalgi et al. 2007; Tsang et al. 2007). Transcription factor and RBP versions of these motifs remain poorly characterized (Joshi et al. 2012), with the exception of the RBP ZFP36 (TTP) in macrophage activation models (Rabani et al. 2014). Nevertheless, the behavioral benefits associated with incoherent feedforward loops include the production of pulse-like patterns, faster response times to stimulation, output noise buffering, and even detection of fold-change in expression (Basu et al. 2004; Mangan et al. 2006; Goentoro et al. 2009; Siciliano et al. 2013). These features would be invaluable for facilitating the rapid production and resolution of the response to Angll stimulation to maintain proper aldosterone homeostasis. However, due to a combination of technical limitations and need for additional experimentation, we do not know which of those features that BTG2 contributes to. $\mathrm{H} 295 \mathrm{R}$ cells are difficult to transfect and it is imperative to develop stable models for controlling gene dose, which we are developing using CRISPR/Cas9. Additionally, we would gain sensitivity by using recently developed methods that provide a direct readout of newly synthesized versus preexisting RNAs in the same sample (Herzog et al. 2017; Schofield et al. 2018). Thus, we are likely underestimating the true number of RNAs exhibiting changes in decay rates during steroidogenesis. Furthermore, we do not know the identity of the transcription factor(s) promoting synthesis of mRNAs encoding prosteroidogenic proteins and BTG2, though SF1 (NR5A1) and CREB1 are the most likely candidates (Caron et al. 1997; Clark and Combs 1999; Nogueira and Rainey 2010; Selvaraj et al. 2018). The RBPs ZFP36L1 and ZFP36L2 are both induced by Angll and bind to AREs in the $3^{\prime}$-UTR of target mRNA to promote decay and may be additional repressors. Consistent with our expectation, ZFP36L1 was shown to suppress ACTH-stimulated STAR mRNA induction in bovine adrenocortical cells and mouse cell lines (Duan et al. 2009). However, this was mediated via ZFP36L1 binding to AREs in an alternative $3^{\prime}$-UTR that we did not detect in our RNA-seq data from $\mathrm{H} 295 \mathrm{R}$ or human adrenocortical cells. Finally, BTG2 depletion only deregulated a subset of mRNAs, which suggests that BTG2 may synergize with specific RNA-decay pathways as previously postulated (Stupfler et al. 2016).

\section{Dynamic RNA regulatory network controlling steroidogenesis}

We have uncovered a novel paradigm by which RBAs and regulated RNA decay control the kinetics of Angll-stimulated gene expression to facilitate the implementation and resolution of prosteroidogenic gene expression and metabolic programs required for proper aldosterone production in humans. In addition to RNA decay factors, we identified the RNA modification enzyme TRUB1 was also a repressor of steroidogenesis. TRUB1 is a pseudouridine synthase that modifies tRNAs and mRNAs (Safra et al. 2017). We also identified numerous activators of aldosterone production. We found that the signaling scaffold protein AKAP1 activates aldosterone production, which is consistent with a proposed role for AKAP1 in promoting the localized translation of STAR mRNA at the mitochondria (Dyson et al. 2008; Grozdanov and Stocco 2012). Additional activators identified include the cytoplasmic RBPs CPEB4, MSI2, and PELO, which regulated stability and translation, as well as, MBNL2 a well-known splicing factor. The majority of these RBPs have not previously been associated with aldosterone production or steroidogenesis. The identification of activators and repressors is not surprising given the dysregulation of aldosterone homeostasis has pathological consequences. Dissecting the role of combinatorial regulation by RBPs in the dynamic steroidogenic regulatory network will undoubtedly reveal novel points of control. Since the adrenal cortex is amenable to the delivery of modified oligonucleotides (Biscans et al. 2019), the RBP-RNA regulatory interactions may be targeted for disruption to precisely and specifically modulate steroidogenesis.

\section{MATERIALS AND METHODS}

See Supplemental Methods for more details. 


\section{Cell culture}

$\mathrm{H} 295 \mathrm{R}$ cells were cultured in complete media containing DMEM: F12 with 10\% Cosmic Calf Serum (Hyclone: SH30087.03) and 1\% ITS+ Premix (Corning: 354352). H295R cells were stimulated with $10 \mathrm{nM}$ Angiontensin II (Sigma: A9525) after being in low sera media for $24 \mathrm{~h}$ (DMEM/F12 with 0.1\% CCS, 1\% ITS).

Primary human adrenal cells were isolated and cultured as described previously (Xing et al. 2010; Rege et al. 2015). Primary adrenal cells were plated at a density of 20,000 cells/well (48 well dish) in growth medium and grown to $60 \%$ confluence after which they were starved in low serum medium $18 \mathrm{~h}$ prior to treatment with either $10 \mathrm{nM}$ Angll or $10 \mu \mathrm{M} \mathrm{ACTH}$.

\section{Gene expression measurements}

H295R cells were collected in TRIzol and RNA was isolated using ZYMO Research DirectZol Miniprep Plus kit following the manufacturer's instructions with on-column DNase I digestion. RNA was collected from ex vivo stimulated primary adrenal cells using the Qiagen RNEasy MiniPrep Plus kit following the manufacturer's instructions and eluted into nuclease-free water.

\section{RT-qPCR}

Reverse transcription was performed using $100 \mathrm{ng}$ of RNA input for the Bio-Rad iScripit kit and qPCR using Bio-Rad iTaq Universal SYBR Green Supermix on a Bio-Rad CFX 384 qPCR instrument. Analysis of qPCR was performed using the delta-delta Cq method normalizing to GAPDH and unstimulated controls.

\section{Metabolic labeling experiments}

We performed 4-thiouridine (4sU) experiments as described previously (Mukherjee et al. 2017). Briefly, H295R cells were treated for a 20-min pulse with $500 \mu \mathrm{M} 4 \mathrm{sU}$. RNA was extracted and split into input and biotinylated samples. The biotinylated RNA was immunoprecipitated using streptavidin beads and both input and immunoprecipitated RNA were subject to rRNA depletion using RiboZero and sequenced using the qRNA-seq kit (BIOO scientific).

\section{RNA-seq and regulatory analysis}

Salmon (Patro et al. 2017) was used for quantifying transcript levels from all libraries using Gencode v26. A custom salmon index containing a Gencode v26 precursor, mature transcripts, and ERCC spike-ins was used as previously described (Mukherjee et al. 2017). All downstream analysis was performed in $R$ and detailed in the Supplemental Methods. Unstimulated (initial) RNA decay rates were estimated using $4 \mathrm{~s} U$ metabolic labeling data and the INSPEcT R package (de Pretis et al. 2015). Overrepresentation of 7 mers was calculated via Cwords (Rasmussen et al. 2013) from 3'UTR sequences ranked by unstimulated RNA decay rates. RBP motifs enrichment was calculated using https://github.com/ TaliaferroLab/FeatureReachR. Determining RNA stability changes during the time course used salmon-quantified intronic and exon- ic reads, adapting the Exon-Intron Split Analysis concept implemented in eisaR (Gaidatzis et al. 2015).

\section{Aldosterone screen}

H295R cells (2.5M) cultured in complete media were electroporated with $10 \mu \mathrm{M}$ siRNA (Thermo Fisher Scientific-see supplement for catalog numbers) and plated in a 96-well plate. After $24 \mathrm{~h}$, half the wells had media that was replaced with low sera media and the other half with low sera media containing Angll. After $24 \mathrm{~h}$, aldosterone levels in the supernatant were measured using Aldosterone Competitive ELISA kit (ThermoFisher) and cell viability was measured from the cells using PrestoBlue reagent (ThermoFisher) by reading fluorescence on a BioTek Synergy HT plate reader. Each plate contained a mock transfection that we normalized to for calculating aldosterone levels in each siRNA experiment while taking plate batch effects and cell viability into account.

\section{DATA DEPOSITION}

Raw sequencing data have been deposited in SRA GSE163801. Code and processed data are available at https://github.com/ mukherjeelab/2021_RNA_PTR-steroid-kinetics.

\section{SUPPLEMENTAL MATERIAL}

Supplemental material is available for this article.

\section{ACKNOWLEDGMENTS}

We would like to thank David Bentley and Lori Sussel for their support, collegiality, and critical review of the manuscript, as well as Uwe Ohler and Austen Gillen for initial support for this study. We thank Bertrand Seraphim for anti-BTG2 antibody. This work was supported by the American Heart Association Predoctoral Fellowship Award 20PRE35220016 (K.W.), the Predoctoral Training Grant in Molecular Biology NIH-T32-GM008730 (K.W.), the University of Colorado Anschutz Medical Campus RNA Bioscience Initiative (N.M., R.F.), Boettcher Foundation Webb-Waring Early Career Investigator Award AWD-103075 (N.M.), and National Institutes of Health DK043140 (W.R.).

Author contributions: N.M. conceived the project; K.Y.W., A.B., A.H., K.W., and J.R. performed experiments and collected data; R.F, K.Y.W., K.R., and N.M. performed formal analysis and conducted the visualization; N.M. wrote the original draft; R.F., K.Y. W., K.R., W.R, and N.M. reviewed and edited the paper; K.Y.W., W.R., and N.M. acquired funding; W.R. and N.M. provided resources; N.M. supervised the project.

Received February 24, 2021; accepted May 20, 2021.

\section{REFERENCES}

Albert TK, Lemaire M, van Berkum NL, Gentz R, Collart MA, Timmers HT. 2000. Isolation and characterization of human orthologs of yeast CCR4-NOT complex subunits. Nucleic Acids Res 28: 809-817. doi:10.1093/nar/28.3.809 
Alkallas R, Fish L, Goodarzi H, Najafabadi HS. 2017. Inference of RNA decay rate from transcriptional profiling highlights the regulatory programs of Alzheimer's disease. Nat Commun 8: 909. doi:10 .1038/s41467-017-00867-z

Bassett MH, Suzuki T, Sasano H, White PC, Rainey WE. 2004. The orphan nuclear receptors NURR1 and NGFIB regulate adrenal aldosterone production. Mol Endocrinol 18: 279-290. doi:10.1210/me $.2003-0005$

Basu S, Mehreja R, Thiberge S, Chen M-T, Weiss R. 2004. Spatiotemporal control of gene expression with pulse-generating networks. Proc Natl Acad Sci 101: 6355-6360. doi:10.1073/pnas .0307571101

Biscans A, Coles A, Haraszti R, Echeverria D, Hassler M, Osborn M, Khvorova A. 2019. Diverse lipid conjugates for functional extra-hepatic siRNA delivery in vivo. Nucleic Acids Res 47: 1082-1096. doi:10.1093/nar/gky1239

Brown JM, Siddiqui M, Calhoun DA, Carey RM, Hopkins PN, Williams GH, Vaidya A. 2020. The unrecognized prevalence of primary aldosteronism: a cross-sectional study. Ann Intern Med 173: 10-20. doi:10.7326/M20-0065

Caron KM, Ikeda Y, Soo SC, Stocco DM, Parker KL, Clark BJ. 1997. Characterization of the promoter region of the mouse gene encoding the steroidogenic acute regulatory protein. Mol Endocrinol 11: 138-147. doi:10.1210/mend.11.2.9880

Clark BJ, Combs R. 1999. Angiotensin II and cyclic adenosine $3^{\prime}, 5^{\prime}-$ monophosphate induce human steroidogenic acute regulatory protein transcription through a common steroidogenic factor-1 element. Endocrinology 140: 4390-4398. doi:10.1210/endo.140 .10 .7085

de Pretis S, Kress T, Morelli MJ, Melloni GEM, Riva L, Amati B, Pelizzola M. 2015. INSPEcT: a computational tool to infer mRNA synthesis, processing and degradation dynamics from RNA- and 4sU-seq time course experiments. Bioinformatics 31: 28292835. doi:10.1093/bioinformatics/btv288

Duan H, Cherradi N, Feige J-J, Jefcoate C. 2009. cAMP-dependent posttranscriptional regulation of steroidogenic acute regulatory (STAR) protein by the zinc finger protein ZFP36L1/TIS11b. Mol Endocrinol 23: 497-509. doi:10.1210/me.2008-0296

Dyson MT, Jones JK, Kowalewski MP, Manna PR, Alonso M, Gottesman ME, Stocco DM. 2008. Mitochondrial A-kinase anchoring protein 121 binds type II protein kinase $A$ and enhances steroidogenic acute regulatory protein-mediated steroidogenesis in MA-10 mouse leydig tumor cells. Biol Reprod 78: 267-277. doi:10.1095/biolreprod.107.064238

Elkon R, Zlotorynski E, Zeller KI, Agami R. 2010. Major role for mRNA stability in shaping the kinetics of gene induction. BMC Genomics 11: 259. doi:10.1186/1471-2164-11-259

Feldman RD. 2014. Aldosterone and blood pressure regulation: recent milestones on the long and winding road from electrocortin to KCNJ5, GPER, and beyond. Hypertension 63: 19-21. doi:10 .1161/HYPERTENSIONAHA.113.01251

Gaidatzis D, Burger L, Florescu M, Stadler MB. 2015. Analysis of intronic and exonic reads in RNA-seq data characterizes transcriptional and post-transcriptional regulation. Nat Biotechnol 33: 722729. doi:10.1038/nbt.3269

Gerstberger S, Hafner M, Tuschl T. 2014. A census of human RNAbinding proteins. Nat Rev Genet 15: 829-845. doi:10.1038/ nrg3813

Goentoro L, Shoval O, Kirschner MW, Alon U. 2009. The incoherent feedforward loop can provide fold-change detection in gene regulation. Mol Cell 36: 894-899. doi:10.1016/j.molcel.2009.11.018

Gross F, Gysel H. 1954. The action of electrocortin in the adrenalectomized dog. Eur J Endocrinol 15: 199-209. doi:10.1530/acta.0 .0150199
Grozdanov PN, Stocco DM. 2012. Short RNA molecules with high binding affinity to the $\mathrm{KH}$ motif of A-kinase anchoring protein 1 (AKAP1): implications for the regulation of steroidogenesis. Mol Endocrinol 26: 2104-2117. doi:10.1210/me.2012-1123

Hao S, Baltimore D. 2009. The stability of mRNA influences the temporal order of the induction of genes encoding inflammatory molecules. Nat Immunol 10: 281-288. doi:10.1038/ni.1699

Hattangady NG, Olala LO, Bollag WB, Rainey WE. 2012. Acute and chronic regulation of aldosterone production. Mol Cell Endocrinol 350: 151-162. doi:10.1016/j.mce.2011.07.034

Herzog VA, Reichholf B, Neumann T, Rescheneder P, Bhat $P$, Burkard TR, Wlotzka W, von Haeseler A, Zuber J, Ameres SL. 2017. Thiol-linked alkylation of RNA to assess expression dynamics. Nat Methods 14: 1198-1204. doi:10.1038/nmeth.4435

Hui J, Reither G, Bindereif A. 2003. Novel functional role of CA repeats and hnRNP L in RNA stability. RNA 9: 931-936. doi:10.1261/rna .5660803

Joshi A, Beck Y, Michoel T. 2012. Post-transcriptional regulatory networks play a key role in noise reduction that is conserved from micro-organisms to mammals. FEBS J 279: 3501-3512. doi:10.1111/ j.1742-4658.2012.08571.x

Keene JD. 2007. RNA regulons: coordination of post-transcriptional events. Nat Rev Genet 8: 533-543. doi:10.1038/nrg2111

Lebrethon MC, Naville D, Begeot M, Saez JM. 1994. Regulation of corticotropin receptor number and messenger RNA in cultured human adrenocortical cells by corticotropin and angiotensin II. J Clin Invest 93: 1828-1833. doi:10.1172/JCl117168

Lin D, Sugawara T, Strauss JF III, Clark BJ, Stocco DM, Saenger P, Rogol A, Miller WL. 1995. Role of steroidogenic acute regulatory protein in adrenal and gonadal steroidogenesis. Science 267: 1828-1831. doi:10.1126/science.7892608

Luscombe NM, Babu MM, Yu H, Snyder M, Teichmann SA, Gerstein M. 2004. Genomic analysis of regulatory network dynamics reveals large topological changes. Nature 431: 308-312. doi:10.1038/nature02782

Mangan S, Itzkovitz S, Zaslaver A, Alon U. 2006. The incoherent feedforward loop accelerates the response-time of the gal system of Escherichia coli. J Mol Biol 356: 1073-1081. doi:10.1016/j.jmb .2005.12.003

Masumura Y, Higo S, Asano Y, Kato H, Yan Y, Ishino S, Tsukamoto O, Kioka $\mathrm{H}$, Hayashi T, Shintani $Y$, et al. 2016. Btg2 is a negative regulator of cardiomyocyte hypertrophy through a decrease in cytosolic RNA. Sci Rep 6: 28592. doi:10.1038/srep28592

Mauxion F, Faux C, Séraphin B. 2008. The BTG2 protein is a general activator of mRNA deadenylation. EMBO J 27: 1039-1048. doi:10 .1038/emboj.2008.43

Milek M, Imami K, Mukherjee N, Bortoli FD, Zinnall U, Hazapis O, Trahan C, Oeffinger M, Heyd F, Ohler U, et al. 2017. DDX54 regulates transcriptome dynamics during DNA damage response. Genome Res 27: 1344-1359. doi:10.1101/gr.218438.116

Monticone S, D’Ascenzo F, Moretti C, Williams TA, Veglio F, Gaita F, Mulatero P. 2018. Cardiovascular events and target organ damage in primary aldosteronism compared with essential hypertension: a systematic review and meta-analysis. Lancet Diabetes Endocrinol 6: 41-50. doi:10.1016/S2213-8587(17)30319-4

Mukherjee N, Calviello L, Hirsekorn A, de Pretis S, Pelizzola M, Ohler U. 2017. Integrative classification of human coding and noncoding genes through RNA metabolism profiles. Nat Struct Mol Biol 24: 86-96. doi:10.1038/nsmb.3325

Mukherjee N, Wessels H-H, Lebedeva S, Sajek M, Ghanbari M, Garzia A, Munteanu A, Yusuf D, Farazi T, Hoell JI, et al. 2019. Deciphering human ribonucleoprotein regulatory networks. Nucleic Acids Res 47: 570-581. doi:10.1093/nar/gky1185

Nanba K, Omata K, Gomez-Sanchez CE, Stratakis CA, Demidowich AP, Suzuki M, Thompson LDR, Cohen DL, Luther JM, Gellert L, et al. 
2019. Genetic characteristics of aldosterone-producing adenomas in blacks. Hypertension 73: 885-892. doi:10.1161/HYPERTENSI ONAHA.118.12070

Nogueira EF, Rainey WE. 2010. Regulation of aldosterone synthase by activator transcription factor/cAMP response element-binding protein family members. Endocrinology 151: 1060-1070. doi:10 .1210/en.2009-0977

Nogueira EF, Bollag WB, Rainey WE. 2009. Angiotensin II regulation of adrenocortical gene transcription. Mol Cell Endocrinol 302: 230-236. doi:10.1016/j.mce.2008.08.024

Palumbo MC, Farina L, Paci P. 2015. Kinetics effects and modeling of mRNA turnover. Wiley Interdiscip Rev RNA 6: 327-336. doi:10 .1002/wrna.1277

Parmar J, Key RE, Rainey WE. 2008. Development of an adrenocorticotropin-responsive human adrenocortical carcinoma cell line. J Clin Endocrinol Metab 93: 4542-4546. doi:10.1210/jc.2008-0903

Patro R, Duggal G, Love MI, Irizarry RA, Kingsford C. 2017. Salmon provides fast and bias-aware quantification of transcript expression. Nat Methods 14: 417-419. doi:10.1038/nmeth.4197

Rabani M, Levin JZ, Fan L, Adiconis X, Raychowdhury R, Garber M, Gnirke A, Nusbaum C, Hacohen N, Friedman N, et al. 2011. Metabolic labeling of RNA uncovers principles of RNA production and degradation dynamics in mammalian cells. Nat Biotechnol 29: 436-442. doi:10.1038/nbt.1861

Rabani M, Raychowdhury R, Jovanovic M, Rooney M, Stumpo DJ, Pauli A, Hacohen N, Schier AF, Blackshear PJ, Friedman N, et al. 2014. High-resolution sequencing and modeling identifies distinct dynamic RNA regulatory strategies. Cell 159: 1698-1710. doi:10 .1016/j.cell.2014.11.015

Rasmussen SH, Jacobsen A, Krogh A. 2013. cWords: systematic microRNA regulatory motif discovery from mRNA expression data. Silence 4: 2. doi:10.1186/1758-907X-4-2

Rege J, Nishimoto HK, Nishimoto K, Rodgers RJ, Auchus RJ, Rainey WE. 2015. Bone morphogenetic protein-4 (BMP4): a paracrine regulator of human adrenal $\mathrm{C} 19$ steroid synthesis. Endocrinology 156: 2530-2540. doi:10.1210/en.2014-1942

Romero DG, Plonczynski M, Vergara GR, Gomez-Sanchez EP, GomezSanchez CE. 2004. Angiotensin II early regulated genes in H295R human adrenocortical cells. Physiol Genomics 19: 106-116. doi:10.1152/physiolgenomics.00097.2004

Romero DG, Rilli S, Plonczynski MW, Yanes LL, Zhou MY, GomezSanchez EP, Gomez-Sanchez CE. 2007. Adrenal transcription regulatory genes modulated by angiotensin $\mathrm{II}$ and their role in steroidogenesis. Physiol Genomics 30: 26-34. doi:10.1152/physi olgenomics.00187.2006

Safra M, Nir R, Farouq D, Vainberg Slutskin I, Schwartz S. 2017. TRUB1 is the predominant pseudouridine synthase acting on mammalian mRNA via a predictable and conserved code. Genome Res 27: 393-406. doi:10.1101/gr.207613.116
Schofield JA, Duffy EE, Kiefer L, Sullivan MC, Simon MD. 2018. TimeLapse-seq: adding a temporal dimension to RNA sequencing through nucleoside recoding. Nat Methods 15: 221-225. doi:10 1038/nmeth.4582

Selvaraj V, Stocco DM, Clark BJ. 2018. Current knowledge on the acute regulation of steroidogenesis. Biol Reprod 99: 13-26. doi:10.1093/biolre/ioy102

Shalem O, Dahan O, Levo M, Martinez MR, Furman I, Segal E, Pilpel Y. 2008. Transient transcriptional responses to stress are generated by opposing effects of mRNA production and degradation. Mol Syst Biol 4: 223. doi:10.1038/msb.2008.59

Shalgi R, Lieber D, Oren M, Pilpel Y. 2007. Global and local architecture of the mammalian microRNA-transcription factor regulatory network. PLoS Comput Biol 3: e131. doi:10.1371/journal.pcbi .0030131

Shim J, Lim H, Yates J R, Karin M. 2002. Nuclear export of NF90 is required for interleukin-2 mRNA stabilization. Mol Cell 10: 13311344. doi:10.1016/S1097-2765(02)00730-X

Siciliano V, Garzilli I, Fracassi C, Criscuolo S, Ventre S, di Bernardo D. 2013. MiRNAs confer phenotypic robustness to gene networks by suppressing biological noise. Nat Commun 4: 2364. doi:10.1038/ ncomms 3364

Smale ST. 2012. Transcriptional regulation in the innate immune system. Curr Opin Immunol 24: 51-57. doi:10.1016/j.coi.2011 .12 .008

Stupfler B, Birck C, Séraphin B, Mauxion F. 2016. BTG2 bridges PABPC1 RNA-binding domains and CAF1 deadenylase to control cell proliferation. Nat Commun 7: 10811. doi:10.1038/ ncomms 10811

Tamayo P, Mootha VK, Mukherjee S. 2005. Gene set enrichment analysis: a knowledge-based approach for interpreting genome-wide expression profiles. Proc Natl Acad Sci 102: 15545-15550. doi:10.1073/pnas.0506580102

Tsang J, Zhu J, van Oudenaarden A. 2007. MicroRNA-mediated feedback and feedforward loops are recurrent network motifs in mammals. Mol Cell 26: 753-767. doi:10.1016/j.molcel.2007.05.018

Wang T, Rowland JG, Parmar J, Nesterova M, Seki T, Rainey WE. 2012. Comparison of aldosterone production among human adrenocortical cell lines. Horm Metab Res 44: 245-250. doi:10.1055/s0031-1298019

Xing Y, Parker CR, Edwards M, Rainey WE. 2010. ACTH is a potent regulator of gene expression in human adrenal cells. $J \mathrm{Mol}$ Endocrinol 45: 59-68. doi:10.1677/JME-10-0006

Xing Y, Edwards MA, Ahlem C, Kennedy M, Cohen A, GomezSanchez CE, Rainey WE. 2011. The effects of ACTH on steroid metabolomic profiles in human adrenal cells. J Endocrinol 209: 327-335. doi:10.1530/JOE-10-0493

Yosef N, Regev A. 2011. Impulse control: temporal dynamics in gene transcription. Cell 144: 886-896. doi:10.1016/j.cell.2011.02.015 

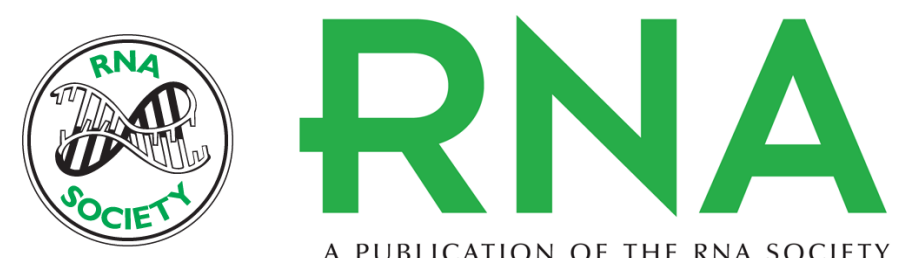

A PUBLICATION OF THE RNA SOCIETY

\section{RNA-binding proteins regulate aldosterone homeostasis in human steroidogenic cells}

Rui Fu, Kimberly Wellman, Amber Baldwin, et al.

RNA 2021 27: 933-945 originally published online June 1, 2021

Access the most recent version at doi:10.1261/rna.078727.121

\section{Supplemental http://rnajournal.cshlp.org/content/suppl/2021/06/01/rna.078727.121.DC1 Material}

References This article cites 61 articles, 9 of which can be accessed free at: http://rnajournal.cshlp.org/content/27/8/933.full.html\#ref-list-1

Open Access Freely available online through the RNA Open Access option.

Creative This article, published in RNA, is available under a Creative Commons License Commons (Attribution 4.0 International), as described at

License http://creativecommons.org/licenses/by/4.0/.

Email Alerting Receive free email alerts when new articles cite this article - sign up in the box at the Service top right corner of the article or click here.

\section{|||||||| Providing Precise Solutions for your research.}

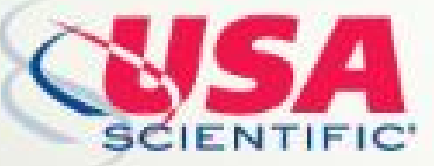

To subscribe to $R N A$ go to:

http://rnajournal.cshlp.org/subscriptions

(C) 2021 Fu et al.; Published by Cold Spring Harbor Laboratory Press for the RNA Society 